\title{
An Investigation on Students' Metacognitive Awareness and Their Achievementin EFL Study
}

\author{
Pu-yu NING ${ }^{1, *}$ \\ ${ }^{1}$ School of Foreign Languages, North China Electric Power University, Beijing, China \\ 1ningpuyu@aliyun.com \\ ${ }^{*}$ Corresponding author
}

Keywords:Metacognitive awareness,Metacognition, EFL, Correlation.

\begin{abstract}
Metacognition has been developing into a key word of the English as Foreign Language (EFL) study in the previoustwo decades. The present paper probed into the relationship between students'metacognitive awareness and their performance in theEFLachievement test. By the employment of the Matecognitive Awarness Inventory (MAI), data analys is showedthatstudents'MAI scores had a significant correlation with their grades in the Chinese National English level test (Band 4). The result indicated thatlanguage learners showing general higher metacognitive awareness performed better in the achivement test. The investigation proved the positive relationshipe between students' metacognitive awareness,especially in the factor of knowledge of cognition, and their accomplishment in EFL study. The paper then proposed that proper integration of metacognition cultivation with university English educationshould be an effective strategy in promoting students' fulfillment in EFL study.
\end{abstract}

\section{Introduction}

The recent two decades have seen metacognition evolves into a key word in the second language acquisition study. More scholars focus on the role of metacognitive awareness in the process of second language study and its relationship with the students'performance.

Metacognitive Awareness Inventory (MAI) developed by Schraw and Dennison[1], is considered as one of the most psychometrically reliable self-report inventories for adolescents and adults. The present research adopted MAI to test students' knowledge of cognition and their regulation of cognition. The positive relationship between metacognitive awareness and performance in the English as Foreign Language (EFL)achievement test was proved by data analysis. The test result indicated that conscious development of metacognitive skills in classroom teaching would bring better performance among EFL students.

\section{Theoretical Background and Literature}

As is often referred to as thinking of thinking, metacognition could be generally defined as a higher level of thinking that monitors and controls over the cognitive processes. According to Ormrod, metacognition is what we know about our cognitive processes and how weuse these processes in order to learn and remember[2]. Some researchers made further analysis and proposed components of metacognition. Flavell is probably the most frequently quoted in metacognition study. He claimed that metacognition consisted of both metacognitive knowledge and metacognitive experiences or regulation[3,4]. According to Flavell, metacognitive knowledge consists of three different kinds of content knowledge, which are declarative knowledge, procedural 
knowledge and conditional knowledge.Declarative knowledge isthe knowledge about learning, the actual information, and cognitive abilities. As manifested in the name, declarative knowledge can be declared. Procedural knowledge, commonly known as know-how, is the knowledge of how to do something, of how to perform atask.Conditional knowled ge is the knowledge about when and why to use or not to use some specific strategies.Metacognitive experiences or regulation, which helps to oversee the process of learning, is composed of the following three basic subcomponents: planning, monitoring and evaluating. Planning includes goal setting, strategy selecting and cognitive resources allocating.Monitoring is the ability to determine theperformance according to the goal.Evaluating is to determine whether thelearning finally satisfiesthe goal set before and whether the regulation process is effective.

As is shown in the above description, from the activity of planning to evaluation, the whole process reflects the learners' ability in self-awareness, self-assessment, self-monitoring and self-coordination. Metacognition plays a critical role in effective learning process.

There have been some studies thatdemonstrated whether students were successful learners when they had better metacognitive awareness. Luo and Gao [5] used Metacognitive Awareness Listening Questionnaire (MALQ) to study the relationship between metacognitive awareness and EFL students' listening achievement, and drew a positive conclusion. Gan [6] also adopted self-designed questionnaire and assessment tests to determine the positive correlation between students'metacognitive strategies and their EFL writing achievement. Zhou [7] based on theoretical study in metacognition, proposed steps and strategies to integrate metacognition development in the online writing course for college EFL students.

The present paper adopted MAI to test students' metacognitive awareness and then tried to find the correlation between students' MAI scores and their performance in EFL achievement test. Based on the data, the study tried to propose that to develop students' metacognition should be a good way to enhance their learning effectiveness and ensure their better performance in EFL study.

\section{Method}

\section{Participants}

The participants were 59 firstyear Chinese university students (46 male, 13 female) who were taking the course of English as a foreign language. They were all native Chinese speakers with EFL study both in their elementary and secondary school level. The average age of the group was 18.98 years $(\mathrm{SD}=0.59)$. The students were asked to complete the MAI during the semester. The MAI was delivered by the lecturer in class. Among all the students, 53 of them completed the MAI.

According to the students' achievements in English level test, 19 studentswhose CET4 grades were above 570 were selected as thehigh achievement Group; 10 students whose CET4 grades were below 500 formed low achievement Group.

\section{Materials and Procedure}

The MAI was used to measure students' metacognitive awareness. The MAI consists of 52 items on a five point Likert scale, namely five levels of awareness:"strongly agree" (5);"agree" (4); "neutral" (3); "disagree" (2); and "strongly disagree" (1). The 52 items are randomly distributed across two major metacognition components: metacognitive knowledge, referred to as knowledge of cognition in MAI, and 
metacoginitiveregulation, referred to as regulation of cognition in MAI. The two components are then broken down into 8 sub-components. Under knowledge of cognition are declarative, procedural and conditional knowledge; under regulation of cognition are planning, organizing, monitoring, debugging and evaluation. There are 17 questions testing theknowledge of cognition in MAI, with a total point of 85. There are 35 questions testing the regulation of cognition with a total point of 175 . The test scores were calculated by adding the scores marked on each item. The higher the scorescalculate, the greater levelthe metacognitive knowledge and metacognitive regulation ability are.

Since the present study was done with first yearnativeChinese university students, the MAI items had been translated into Chinese but provided with both English and

Chinese. Students were delivered the MAI item sheet face to face in class. They were asked to complete the item sheet with their student ID numbersmarked on the sheets so that their MAI scores could be associated with their English level test grades, which were available within the same semester. There was no bonus on their finals if the students finish their MAI. Among 59 students, 53 completed the MAI sheets.

The English level test used in the study is College English Test (CET) organized by the Minis try of Education in China. With the first pilot test conducted in 1986, the CET has developed asthe dominant Chinese national English Level test designed to examine the English proficiency of non-English major Chinese undergraduate and postgraduate students. Since 2005, the Test has experienced twice major reforms both in formats and grading system. Presently, the Test includes writing, listening, reading, and translation sections. Listening and reading weights $35 \%$ of the total test score respectively, while writing and translation take up the rest 30\%. The latest reform in CET grading system settled that test scores were graded on a curved scale with the highest possible is 710 and the lowest 290 (finish all questions but all wrong).

Students' MAI test results were collected and transferred to SPSS data. MAT total scores are measured, and scores were alsomeasured by two componentsrespectively, namely knowledge of cognition (KC) and regulation of cognition (RC). Considering that previous studies on metacognition and students' listening achievements showed correlations among subcomponents [5], the sum of each subcomponent, namely declarative knowledge (DK), proced ural knowled ge (PK), cond itional knowled ge (CK), planning (PL), organizing (Str), monitoring (Mo), debugging (DB) and evaluation (Ev), were also calculated.The CET grades of the students were presented in four different items, namely, the total score (CET4), listening (CET listening), reading (CET reading), writing and translation (CET trans.\& writing). Statistical analysis was conducted between the MAI components and students' CET grades.

\section{Results}

\section{Correlations between MAIand Students'EFL Achievement}

For the 53 students who presented valid MAI scores, the mean MAI score was 187.09. The mean for the knowled ge of cognition factor was 62.81, and the mean for regulation of cognition factor was 124.28. Table 1shows the means and standard deviations of the MAI. 
Table 1. Means and Standard Deviations of the MAI and the MAI components

\begin{tabular}{lll}
\hline & Mean & SD \\
\hline MAI & 187.09 & 21.45 \\
Knowledge of cognition (KC) & 62.81 & 8.02 \\
Regulation of cognition (RC) & 124.28 & 14.92 \\
\hline
\end{tabular}

The Pearson correlation was conducted in order to detect the correlation between the knowledge of cognition andthe regulation of cognition. A significant correlation between the knowledge of cognition factor and the regulation of cognition is found with $\mathrm{r}=0.725, \mathrm{p}<0.01$. Correlations between students MAI scores and their EFL achievements in CET4 tests were conducted in the same way. See Table 2.

Table 2. Correlations between MAT and CET 4 grades

\begin{tabular}{|c|c|c|c|c|c|c|c|}
\hline & MAI & $\mathrm{KC}$ & $\mathrm{RC}$ & CET 4 & $\begin{array}{l}\text { CET4 } \\
\text { listening }\end{array}$ & $\begin{array}{l}\text { CET4 } \\
\text { reading }\end{array}$ & $\begin{array}{l}\text { CET } 4 \\
\text { tran.\&writing }\end{array}$ \\
\hline MAI & 1.000 & $.878^{* *}$ & $.966^{* *}$ & $.307^{*}$ & .223 & .084 & $.357^{* *}$ \\
\hline $\mathrm{KC}$ & $.878^{* *}$ & 1.000 & $.725^{* *}$ & $.387^{* *}$ & $.271^{*}$ & .121 & $.449^{* *}$ \\
\hline $\mathrm{RC}$ & $.966^{* *}$ & $.725^{* *}$ & 1.000 & .234 & .175 & .055 & $.272^{*}$ \\
\hline CET 4 & $.307^{*}$ & $.387^{* *}$ & .234 & 1.000 & $.840^{* *}$ & $.648^{* *}$ & $.720^{* *}$ \\
\hline CET 4 & .223 & $.271^{*}$ & .175 & $.840^{* *}$ & 1.000 & $.369^{* *}$ & $.369^{* *}$ \\
\hline \multicolumn{8}{|c|}{ listening } \\
\hline $\begin{array}{l}\text { CET4 } \\
\text { reading }\end{array}$ & .084 & .121 & .055 & $.648^{* *}$ & $.369^{* *}$ & 1.000 & .234 \\
\hline $\begin{array}{l}\text { CET } 4 \\
\text { trans.\& }\end{array}$ & $.357^{* *}$ & $.449^{* *}$ & $.272^{*}$ & $.720^{* *}$ & $.369^{* *}$ & .234 & 1.000 \\
\hline writing & & & & & & & \\
\hline
\end{tabular}

** Correlation is significant at the 0.01 level

*Corre lation is significant at the 0.05 level

A significant correlation was found between the total score of the MAI and the CET4 grades; however, among the two major components of Metacognitive awareness, only knowledge of cognition shows correlation with CET4, CET listening, as well as translation and writing grades.Regulation of cognition didn't show significant correlation with CET4 grades, but it showed a modest correlation with CET4 writing and translation grades, which takes up $30 \%$ of the total CET4 grades. Besides the results presented in Table 2, three subcomponents, DK, CK and Mo, showed significant correlation with students' CET4 grades: $r=0.414, \mathrm{p}<0.01 ; \mathrm{r}=0.304, \mathrm{p}<0.05 ; \mathrm{r}=0.298$, $\mathrm{p}<0.05$ respectively.

Although the result didn't show strong correlation between each component of metacognition and every item on CET4 grades, it still presented the relation between both the knowledge of cognition and regulation of cognition ofthe MAI and general measures of EFL achievement. 


\section{Different MAI Scores between the High Achievement Group and Low Achievement Group:}

Disparities in scores on theMAI between high achievementgroup and low achievementgroupwere found. See Table 3.

Table 3. MAI Means and Standard Deviation of the high and low achievement students

\begin{tabular}{lcccccc}
\hline & MAIMean & MAI SD & KC Mean & KC SD & RC Mean & RC SD \\
\hline $\begin{array}{l}\text { High } \\
\text { achievement }\end{array}$ & 192.35 & 20.306 & 65.30 & 8.04 & 127.05 & 13.99 \\
$\begin{array}{l}\text { Low } \\
\text { achievement }\end{array}$ & 181.10 & 21.835 & 59.60 & 6.535 & 121.50 & 16.201 \\
\hline
\end{tabular}

\section{Discussion}

The present study aimed to prove the relationship between Chinese EFL students' metacognition and their EFL achievement. The research also proved the significant correlations between knowledge of cognition and regulation of cognition, as had been found in earlier research.Students' metacognitive awareness significantly related to students' performance in some particular aspect of their English study[5,6]. The MAI also proved to have a significant correlation with students' English achievement test grades. Specifically, knowledge of cognition was significantly correlated with CET4 test grades, especially in the listening, translation and writing parts, which all together take up $65 \%$ of the total test grades. Regulation of cognition showed significant correlation with the translation and writing part of the test.

The study result seemed to suggest that the MAI score better correlated with student's translation and writing grades in their achievement test, both in knowledge of cognition and regulation of cognition. Translation and writing part in CET4 examines EFL students' language output in English ability. In light of this, it could be assumed that metacognitive awareness might exert more influence on students' language output in EFL study.

The study also found the clear differences in metacognition, both the knowledge of cognition and the regulation of cognition, between high achievement EFL students and low achievement EFL students.

The positive relationship between the MAI and students' EFL achievement proved in the research suggested that proper integration of metacogintion cultivation in EFL teaching could serve as a crucial impetus to enhance student's EFL performance. The development of students' metacognitive awareness is supposed to be effective to improve students' EFL achievement.

Thus, practical strategies shall be employed in setting up classroom in order to facilitate the development of students' metacognitive skills in EFL learning. For example, students could be recommended to make study plan at the beginning of each semester, and during the study process, some self observation and self evaluation could be adopted in specifically designed activities. Finally, after the achievement test students could be asked to make reflective report over their study experience and their grades achieved. Meanwhile, significant correlation between the MAI and student's EFL performance in their achievement test could be considered as a supplementary criterionwhen university tries to screen students for advanced level study. 


\section{Future Study}

The limitation of the present study was that the students participating might not be able to represent all youngEFL learners in China since they wereall first year university students with similar age. Besides, imbalanced education resources from elementary to tertiary level across the nation might bring the result that higher performing students have been overrepresented in the sample since they all presently study in Beijing, the capital city of China that enjoys advantage in education resources. Finally, associationsamong other variables, which might be confounding factors for their performance in EFL study, may be further determined, for example, the students 'initialEnglish levels before university study, students' motivation in studyand their native places etc.

Besides, subcomponents like declarative knowledge (DK), conditional knowledge (CK) and monitoring skill (Mo) were proved to have strong correlation with students' achievement. Thus, when adopting metacognition development strategies in classroom, control group could be set up to further determine whether metacognitive instructions, and which kind of instruction(s) could improve students' EFL achievements. Since students would also develop their study habits and experience in university, follow up study could also be conducted in the future to detect the metacognition development and its relation with students'improvement in EFL study. Above all, sample size is another critical factor in future studies. Much larger and random EFL student sample should be examined to determine the robust correlation between metacognition and EFL students' achievement.

\section{Ackno wledge ment}

This research was financially supported by Beijing cooperative project special funds.

\section{References}

[1] G.Schraw, \&R.S.Dennison, Assessing metacognitive awareness. Contemporary Education Psychology, 19(1994)460-475.

[2] J.E.Ormrod, Human Learning. Upper Saddle River, Pearson Prentice Hall, New York, 2004.

[3] J. H. Flavell,. Metacognition and cognitive monitoring: A new area of cognitive-developmental inquiry. American Psychologist, 34(1979), 906-911.

[4] J. H.Flavell, Speculations about the nature and de velopment of metacognition, in F. E. Weinert\& R. H. Kluwe (Eds.), Metacognition, Motivation and Understanding, Lawrence Erlbaum Associates, Hillside, New Jersey, 1987, pp. 21-29

[5] L.Luo, CY.Gao, Correlation study on university students' metacognitive awareness and achievements, Journal of Southwest University for Nationalities. 9 (2011) 100-102 (In Chinese)

[6] LH. Gan, Correlation study between metacognitive strategies and English writing, Journal of North University of China (Social Science Edition), 25(2009) 21-25 (In Chinese)

[7] M.Zhou, Study on the application of metacognitive awareness in the teaching of college English writing, China Electric Power Education. 261(2013) 167-168 (In Chinese) 